1 Ridolfi RL, Bell WR. Thrombotic thrombocytopenic purpura. Report of 25 cases and review of the literature. Medicine 1981; 60: 413-28.

2 Bell Wr, Braine HG, Ness PM, Kuckler TS. Improved survival in thrombotic thrombocytopenic purpura-hemolytic uremic syndrome: clinical experience in 108 patients $N$ Engl f Med 1991; 325: 398-403.

3 Harrison CN, Lawrie AS, Iqbal A, Hunter A, Machin SJ. Hasma exchange with solvent/detergent - treated plasma of resistant thrombotic thrombocytopenic purpura. $B r \quad f$ Haematol 1996; 94: 756-8.
4 Rose M, Eldor A. High incidence of relapses in thrombotic thrombocytopenic purpura. Am $\mathcal{F}$ Med 1987; 83: 437-44. 5 Ridolfi RL, Hutchins GM, Bell WR. The heart and cardiac conduction system in thrombotic thrombocytopenic purpura. A clinicopathological study of 17 autopsied patients. Ann Intern Med 1979; 9: 357-63.

6 Eagle KA, Fallon JT. A 41-year-old woman with thrombocytopenia, anemia, and sudden death. $N$ Engl $f$
Med 1994; 331: $661-7$.

\title{
Epigastric pain and a left upper quadrant mass in an elderly woman
}

\author{
R Joarder, AC Harris, M Gibson, A Al-Kutoubi
}

An 81-year-old woman presented to her general practitioner complaining of epigastric discomfort radiating to her back. This was associated with weakness, fatigue, diarrhoea, and a microcytic anaemia (haemoglobin $8.6 \mathrm{~g} / \mathrm{dl}$ ). On examination, she was found to have a smooth mass in the left hypochondrium. Upper gastrointestinal tract endoscopy was normal. An abdominal ultrasound scan showed an $11 \times 7 \times 5 \mathrm{~cm}$ mass in the left hypochondrium which had air running through it. The liver, spleen and kidneys appeared normal. A computed tomography (CT) scan was performed (figure 1).

\section{Department of Diagnostic Radiol- ogy, St Mary's NHS Trust Hospital, Praed Street, London W2 1NY, UK R Joarder AC Harris M Gibson \\ A Al-Kutoubi}

Accepted 16 April 1997

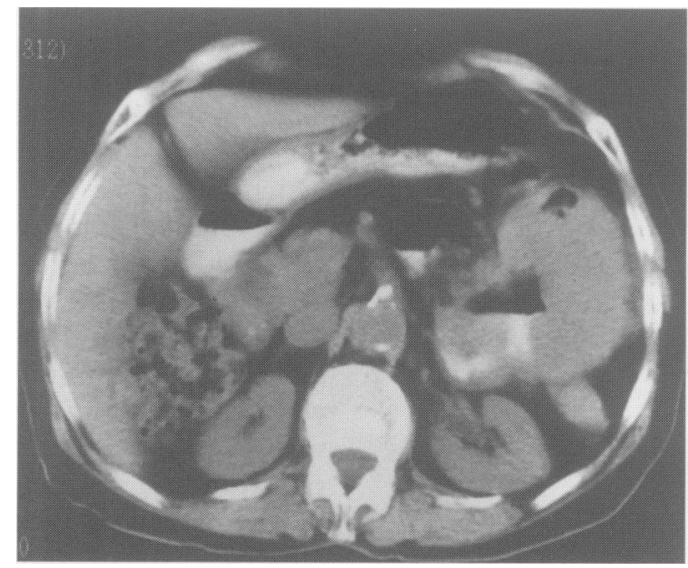

\section{Questions}

1 What are the findings on the CT scan (figure 1)?

2 What would be your next investigation? 3 What is the differential diagnosis?
Figure 1 CT scan through the upper abdomen following oral and intravenous contrast 
Answers

\section{QUESTION 1}

There is a large left upper quadrant mass of soft tissue density (arrows) which appears to arise from the proximal jejunum (figure 2).

\section{QUESTION 2}

A small bowel barium investigation was the next to be carried out (figure 3). This barium follow-through showed that the jejunum just distal to the duodeno-jejunal flexure was irregularly narrowed (arrows) with a surrounding, shouldered soft tissue mass. This segment of jejunum showed abnormal peristalsis.

\section{QUESTION 3}

Causes of proximal jejunal mass include:

Benign tumours (eg, adenomatous polyps, leiomyoma, neurofibroma, lipoma, haemangioma and less commonly mesenchymal lesions). These are usually asymptomatic and detected incidentally. On barium studies, they are most commonly seen as filling defects.
Figure 2 The same CT scan as figure 1 with arrows pointing to a soft tissue mass arising from the proximal jejunum

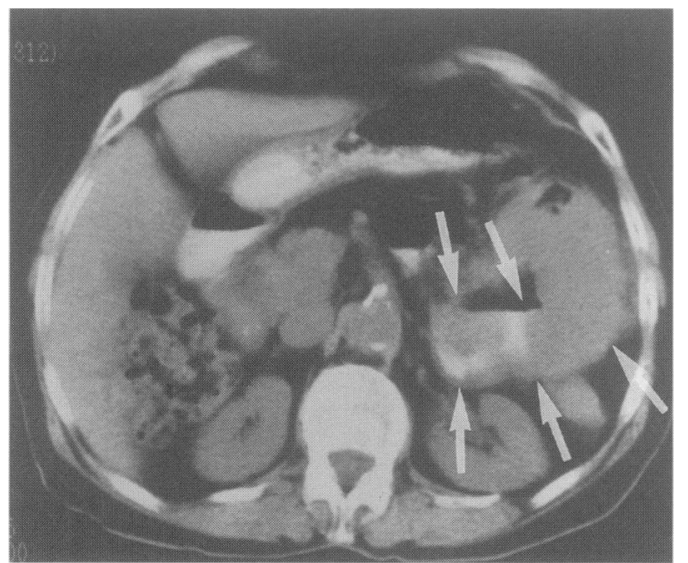

Figure 3 A barium follow-through examination showing an irregular shouldered narrowing of the proximal jejunum (arrows)

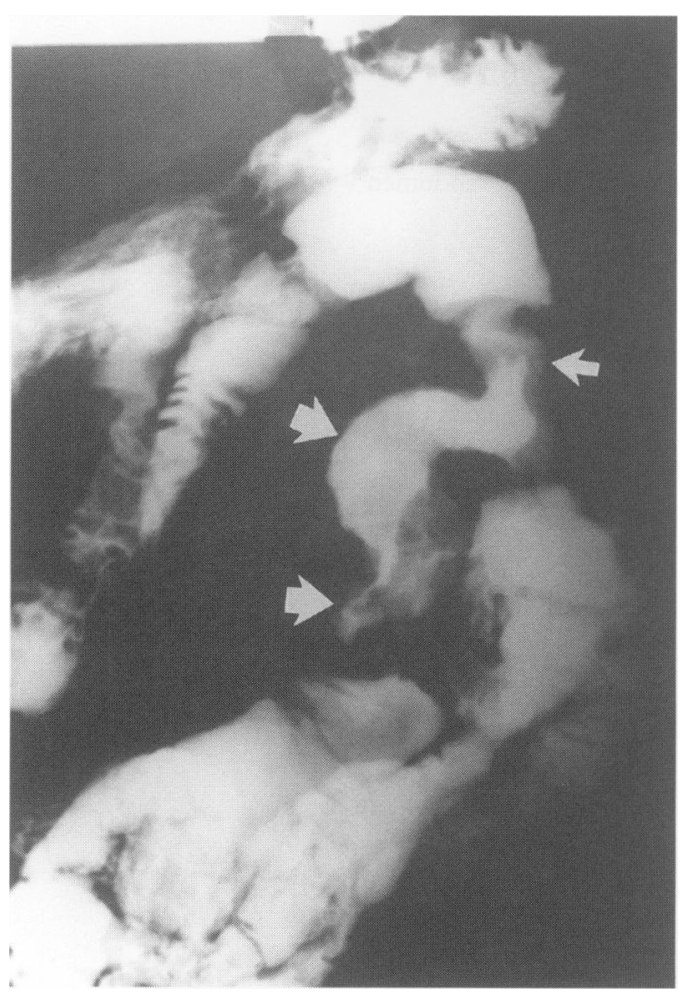

Malignant tumours (eg, adenocarcinoma, leiomyosarcoma and lymphoma). Primary adenocarcinoma of the jejunum and ileum constitutes $15 \%$ of intestinal neoplasms. ${ }^{1}$ Rare before 30 years of age, the peak incidence is in the sixth decade. Adenocarcinoma is more common in males than females. The radiological signs are similar to carcinoma of the colon. Barium studies demonstrate strictures with destruction of the mucosa and shouldering of the margin, ulcerating lesions or polypoid masses. Leiomyosarcoma is more common in males with a peak incidence in the fifth to seventh decades. These may be identified as a large mass displacing adjacent loops usually with a large barium-filled cavity. Intestinal lymphoma is more commonly found in males in the fourth to sixth decades. It is often indistinguishable radiologically from other neoplastic lesions. Large central ulcer craters are frequent. Lymphomatous neoplasms may also be lobulated. They may be multiple and are seen more frequently in the ileum than the jejunum. ${ }^{2}$

Carcinoid tumours, which nearly always occur in the ileum, particularly the distal ileum. They represent the most common primary small bowel tumour-one third of all small bowel neoplasms. They can occur at any age but metastasising tumours are common in the elderly with an equal incidence between males and females. Radiological signs include either an intramural or intraluminal filling defect. They may be multiple. Local tumour spread may be associated with a fibrotic reaction which may cause narrowing of the small bowel with fixation and separation of loops. The carcinoid syndrome, with flushes, bronchial constriction, heart valve lesions and diarrhoea, usually occurs with widespread hepatic metastases. Less commonly, small bowel carcinoid with direct venous drainage into the inferior vena cava or azygous vein may also produce the syndrome. Treatment involving surgical removal of a single carcinoid tumour may be curative. More commonly, patients present with metastatic disease when surgery and or chemotherapy may then be used to reduce tumour bulk. Selective embolisation of hepatic lesions can also utilised.

Metastatic neoplasms The most usual sites of origin are malignant melanoma, ovary, pancreas, stomach, colon, breast, lungs and uterus. ${ }^{3,4}$ Metastatic lesions may present as solitary filling defects which may have any of the features of a primary neoplasm.

Inflammatory lesions Crohn's disease may present as a single short stricture but usually involves the distal ileum. Infection, such as tuberculosis and amoebiasis, involves the terminal ileum preferentially.

\section{Final diagnosis}

Malignant carcinoid tumour

Keywords: carcinoid tumour, jejunal mass 
1 Papadopoulos VD, Nolan DJ. Carcinoma of the small intestine. Clin Radiol 36: 409-13.

2 Koehler R. Small bowel neoplasms (lymphoma) In: PC Freeney, GW Stevenson, eds. Alimentary tract radiology, Vth edn, 1994; pp 634-9.
3 Marshack RH, Khilnani MT, Eliasoph J, Wolf BS. Metastatic carcinoma of the small bowel. $A \mathcal{F} R$ 1965; 94, 385-94.

4 Beckley DE. Alimentary tract metastases from malignant melanoma. Clin Radiol 1974; 25: 385-9.

\title{
Sudden weakness in a young Chinese man
}

\author{
Venkat RR Kodali, Ben Jeffcote, Roy B Clague
}

A 31-year-old man from mainland China presented with sudden onset weakness of limbs of eight hours duration. He had woken up from bed with weakness. He was not on any medication; both parents and brother are healthy. On examination he had motor weakness with diminished deep jerks. Non-tender hepatomegaly was present.

Investigations revealed normal blood counts, urea, creatinine, glucose and electrolytes were normal, creatine kinase $1105 \mathrm{U} / 1$ (reference range: 10-195), alanine transaminase $68 \mathrm{U} / 1$ (540), aspartate transaminase $49 \mathrm{U} / 1(6-37)$, alkaline phosphatase $180 \mathrm{U} / 1(98-279)$, glutamyl transferase $128 \mathrm{U} / 1(10-50)$, plasma viscosity $1.57 \mathrm{mPas}$ at $25^{\circ} \mathrm{C}(1.50-1.72)$. Electrocardiograms were normal and chest X-ray was clear. Peak flow was $560 \mathrm{l} / \mathrm{min}$.

He recovered naturally and, while awaiting other results, was discharged. He was re-admitted within a week with hypokalemia of $1.8 \mathrm{mmol} / \mathrm{l}(3.5-5.5)$. The outstanding investigations were by then available. Free thyroxine $65.6 \mathrm{pmol} / \mathrm{l}(9-24)$, thyroid-stimulating hormone (TSH) $<0.05 \mathrm{mU} / 1(0.49-4.67)$, free tri-iodothyronine $24 \mathrm{pmol} / 1$ (4-8.3). Antiparietal cell antibodies were positive, thyroid autoantibodies were not detected, ds-DNA, antinuclear antibodies, antismooth muscle, mitochondrial and extractable nuclear antigen, and Jo1 were negative. Muscle biopsy did not show significant abnormalities. Electromyography and nerve conduction studies were normal. By this time creatine kinase levels had normalised. Hepatitis B surface antigen and anti- $\mathrm{Hb} \mathrm{E}$ were positive and $\mathrm{Hb} \mathrm{E}$ antigen was negative.

Department of Medicine, Noble's Isle of Man Hospital, Douglas, Isle of Man IM1 4QA, UK

VRR Kodali

B Jeffcote RB Clague

Accepted 16 April 1997

\section{Questions}

1 What is your diagnosis?

2 How would you treat the weakness and what complications may arise from treatment?

3 Will the patient be prone to further paroxysmal weakness?

4 What other history would you consider important in this type of hepatitis and what will you inform the patient? 